\title{
Thermodynamic Research of Solubility of Irradiate Cross-linked Copolymers in Mix Butadiene Nitrile with Polyvinylchloride
}

\author{
S. M. Mammadov ${ }^{1, *}$, S. A. Rzayeva ${ }^{1}$, A. A. Garibov ${ }^{1}$, E. O. Akperov ${ }^{2}$, J. S. Mammadov ${ }^{1}$ \\ ${ }^{1}$ Institute of Radiation Problems of ANAS, Baku, AZ1143, Azerbaijan \\ ${ }^{2}$ Baku State University, Baku, AZ 1143, Azerbaijan
}

\begin{abstract}
As shown, Energy effect have definition role for solubility of irradiate copolymer in mix butadiene nitrile rubber with polyvinylchloride, entropic effect remaining negative in initial polymer do not promote to solubility process. The experiments showed that increasing of radiation dosage during cross linking reduces characteristic viscosity of solutions and influence to change other physical-chemical properties of cross- linked copolymers.
\end{abstract}

Keywords Solubility, Radiation, Copolymer, Butadiene Nitrile Rubber, Polyvinyl Chloride, Enthalpy, Characteristic Viscosity

\section{Introduction}

Despite the progress in study of physical-chemical properties of cross-linked copolymers which synthesized by radiation methods, such as the property of their solubility are not sufficiently explored. It's known that, secondary processes (cross-linking or destruction), occurring in polymer components by influence ionize radiation, depends on dosage and power of radiation of the same system copolymers can be form products with solubility, restricted solubility or non solubility properties even in solvents which are common solvents for all polymers[1-9]. Previously we and others[10, 11] have shown that, cross-linking polymers (elastopolymers) are characterized by very limited solubility in comparison with raw materials as result the influence of one compound to another. In this connection, studies of solubility of cross-linking copolymers are of interest which have the same solubility in raw materials and have the same solvent. This work describe the results of thermodynamical research irradiated cross-linked copolymers in mix butadiene nitrile rubber (BNR, SKN-40) with polyvinylchloride (PVC) depended on radiation dosage.

\section{Experimental Part}

* Corresponding author:

Shiraz_mm55@mail.ru

Published online at http://journal.sapub.org/materials

Copyright (C) 2012 Scientific \& Academic Publishing. All Rights Reserved
Copolymerization of BNR with PVC was carried out by mixing rubber latex with PVC (80:20). The mixture was filled with antirad (eg. 2-amino -4.6-bis-trichlomethylsym triasine) to reduce irradiation dosage because 2-amino-4.6-bis-trichlomethylsym triasine radiation sensitive monomer and coagulated with aluminum salts at $313-323 \mathrm{~K}$. the formed grit was washed with water and dried by $343 \mathrm{~K}$. Irradiation occurred by $\gamma$-rays $\mathrm{Co}^{60}$ in dosage interval $10-50 \mathrm{kGy}$ dose power $200 \mathrm{r} / \mathrm{s}$, by irradiation temperature $313 \mathrm{~K}$. The methods of experiments and the results of synthesis had been previously shown by us[12].

\section{Results and Discussion}

Thermal effect of irradiated copolymers defined by $298 \mathrm{~K}$ in microcalorimeter described in[13]. The scaling factor of calorimeter was equal to $0.0637 \mathrm{cal} / \mathrm{mm}$. Solution heat was defined for initial polymer BNR (70\%) and second copolymer containing PVC $30 \%$. The graphic method crossing clippings were used for defining the change of partial enthalpy of solvent (toluene) $\Delta \bar{H}$ in system BNR-toluene and copolymer-toluene[14].

Isotherms of sorption of toluene, BNR and copolymer were determined by the installation of sorption. For defining dependence of changing partial enthalpy toluene $T \Delta \bar{S}$ from solution concentration was used value of $\Delta \bar{Z}$ counted by sorption isotherms according to the known equation. The value of $\Delta \bar{H}$ was found by graphic chart.

The density of copolymers was determined by hydrostatic weighting method[15], based on the definition of the mass loss of sample immersed in the liquid, which is inert in relation to copolymers. 
The solubility of irradiated copolymers SKN-40PVC30 was qualitatively studied. The different solvents were tested. It was found that irradiated copolymers dissolve in solvents such as toluene, dichloroethane, solvent, methyl ethyl ketene, dioxane, chloroform. These dates show that obtained copolymer didn't loose its ability to dissolution in the result of reaction, because their initial components nearby solubility and have the same solvents. But, as known, strictly scientific criteria dissolving ability of solvent is a change of Gibbs free enthalpy of solvent in system polymer-solvent include both sides of dissolve processes: enthalpy and entropy changes.

Table 1 shows reaction BNR with PVC by influence ionized irradiation generates some decrease affinity copolymer to toluene compare initial polymer, as shown decrease value of $\Delta \bar{Z}$, for copolymer SKN-40+PVC-30, which contain $30 \%$ of PVC $\Delta \bar{Z}$ was counted by sorption isotherm (figure 1).

Table 1. Changing of free energy $\Delta \bar{Z}$ of Methyl ethyl ketene by dissolving BNR and irradiated copolymers BNR-PVC

\begin{tabular}{|c|c|c|c|c|}
\hline \multirow{2}{*}{$\mathrm{x} / \mathrm{m}$} & \multicolumn{2}{|c|}{$\mathrm{BNR}$} & \multicolumn{2}{c|}{$\begin{array}{c}\text { Irradiated copolymer } \\
\text { (BNR : PVC) (70:30) }\end{array}$} \\
\cline { 2 - 5 } & $\mathrm{P}_{1} / \mathrm{P}_{1}{ }^{0}$ & $\Delta \bar{Z}, \frac{\mathrm{cal}}{\mathrm{mol}}$ & $\mathrm{P}_{1} / \mathrm{P}_{1}{ }^{0}$ & $\Delta \bar{Z}, \frac{\mathrm{cal}}{\mathrm{mol}}$ \\
\hline 0,01 & 0,55 & $-465,2$ & 0,6 & $-512,4$ \\
\hline 0,03 & 0,57 & $-337,3$ & 0,69 & $-345,1$ \\
\hline 0,05 & 0,59 & $-310,6$ & 0,77 & $-218,3$ \\
\hline 0,07 & 0,60 & $-292,4$ & 0,82 & $-168,1$ \\
\hline 0,1 & 0,65 & $-236,5$ & 0,85 & $-126,8$ \\
\hline
\end{tabular}

$\mathrm{x} / \mathrm{m}$ - amount of absorbed MEK per 1 $1 \mathrm{~g}$ polymer $\mathrm{P}_{1} / \mathrm{P}_{1}{ }^{0}$ - relative elasticity

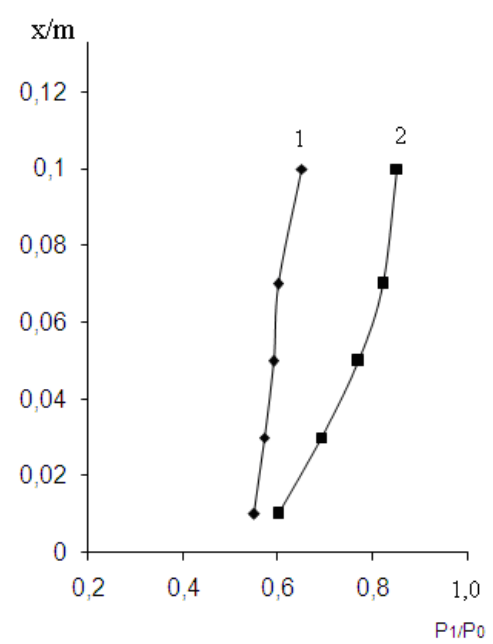

Figure 1. The dependence of the relative steam tension of toluene/MEC $\left(\mathrm{P}_{1} / \mathrm{P}_{1}{ }^{0}\right)$ to the amount of absorbed toluene per $\mathrm{g}$ of polymer $\mathrm{x} / \mathrm{m}$. 1-BNR; 2irradiated copolymer containing $30 \% \mathrm{PVC}$

But, according to curve figure 2 enthalpy component of thermodynamic potential increase by its absolute value, which should promote solution processes.

Entropy component $T \Delta \bar{S}$ (figure 3) does not foster to solubility remaining negative as in initial polymer.

The data presented above it is possible to can conclude that in solution of current copolymer defined role play energetic effect and small difference in change of thermo dynamical functions for copolymers in comparison initial polymer shows the absence of violent changes in solubility of initial polymer in the result of radiation-chemical reaction.

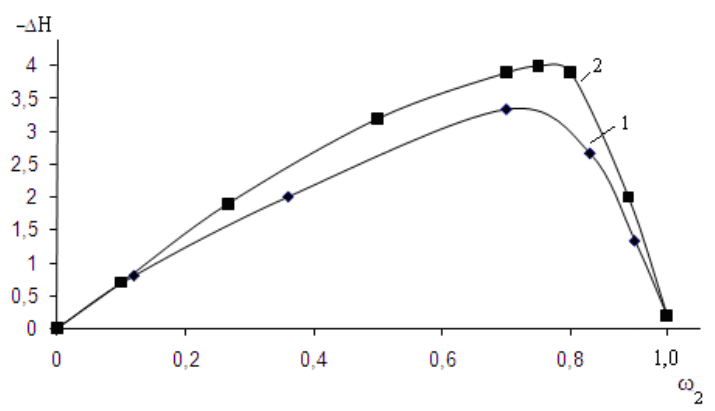

Figure 2. Dependence of $\Delta \mathrm{H}=f\left(\omega_{2}\right)$ for systems MEK - BNR and MEC - irradiated copolymer containing 30\% PVC

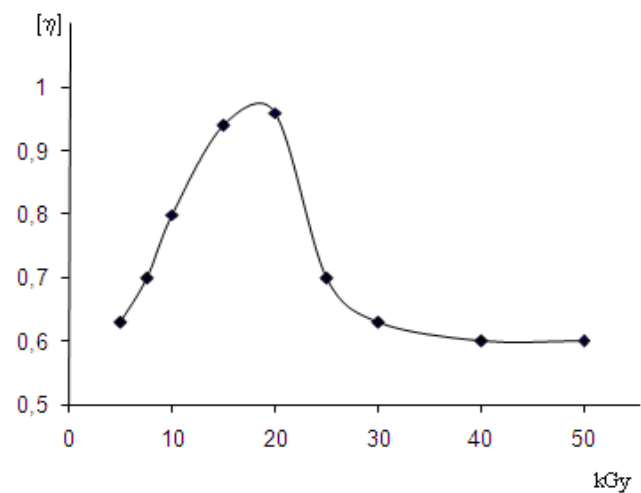

Figure 3. Changing of characteristic viscosity $(\eta)$ of solutions of irradiated copolymers BNR-PVC (in acetone), depend on by irradiation doses ( $\mathrm{kGy}$ )

BNR has isomeric structure, which consist of cis $-1,2$ isomer is $14.3 \%$, cis $-1,4$ isomer is $14.8 \%$ and trans- 1,4 isomer is $70 \%$. The number of chain of mesh in initial BNR is low; as a result it must increase solubility and high value of thermal effect diffusion and solution. Really, as shown in table 2, BNR dissolves in Methyl ethyl Ketene with major positive thermal effect $+7,2 \mathrm{cal} / \mathrm{h}$. Its copolymers also dissolute with heat, but in copolymers with increase content of PVC are observed decrease of thermal effects compared to initial BNR. Moreover, this pattern is observed for the copolymers obtained at different doses and for samples obtained at the same radiation dose. Such character of the change of the thermal effects is because that the MEK interacts more vigorously in a mixture of cross-linked copolymer with BNR more than non-cross-linked and apparently reduction of thermal effects making a seal in the initial polymer structure due to cross-linking, since the increase in density in a series of copolymers corresponds to a decrease of integral heats of dissolution. As shown the BNR dissolves in toluene with the thermal effect of $4.5 \mathrm{cal} / \mathrm{h}$, and in the copolymer SKN-40+PVC-30 with $6.1 \mathrm{cal} / \mathrm{h}$ (table 2). Therefore, one should expect that with increasing content of PVC in a series of copolymers the thermal effect of dissolution will increase. The experimental data in some cases confirm this, but detect any general pattern is not 
possible. The change in physical chemical properties of the irradiated polymer should affect the changing character occurring in the copolymers as a result of radiation, and radiation dose used in the cross-linking.

Table 2. Integral heat of solution and density irradiated copolymers BNR-PVC

\begin{tabular}{|c|c|c|c|c|c|}
\hline \multirow{3}{*}{$\begin{array}{c}\text { Irradiation } \\
\text { dose, kGy }\end{array}$} & \multicolumn{2}{|c|}{$\begin{array}{c}\text { Contain in } \\
\text { copolymer } \\
\text { BNR and PVC, }\end{array}$} & \multicolumn{2}{|c|}{$\bar{Q}, \mathrm{cal} / \mathrm{g}$} & \multirow{2}{*}{$\mathrm{d}, \mathrm{g} / \mathrm{cm}^{3}$} \\
\cline { 2 - 5 } & BNR & PVC & MEK & Toluene & \\
\hline 0 & 0 & & 35,8 & 41,3 & 0,8452 \\
\hline \multirow{4}{*}{10} & 90 & 10 & 32,3 & 38,2 & 1,1396 \\
\cline { 2 - 6 } & 80 & 20 & 27,4 & 36,5 & 1,1357 \\
\cline { 2 - 6 } & 70 & 30 & 25,3 & 35,9 & 1,1343 \\
\cline { 2 - 6 } & 60 & 10 & 23,0 & 35,3 & 1,1340 \\
\hline \multirow{4}{*}{20} & 90 & 10 & 30 & 37,5 & 1,1426 \\
\cline { 2 - 6 } & 80 & 20 & 25 & 32,3 & 1,1278 \\
\cline { 2 - 6 } & 70 & 30 & 22,3 & 31,6 & 1,1224 \\
\cline { 2 - 6 } & 60 & 40 & 20,6 & 31,0 & 1,1201 \\
\hline \multirow{4}{*}{30} & 90 & 10 & 27,4 & 36,3 & 1,1410 \\
\cline { 2 - 6 } & 80 & 20 & 23,8 & 31,2 & 1,1200 \\
\cline { 2 - 6 } & 70 & 30 & 19,4 & 28,5 & 1,1116 \\
\cline { 2 - 6 } & 60 & 40 & 16,3 & 26,2 & 1,1072 \\
\hline \multirow{4}{*}{40} & 90 & 10 & 21,8 & 32,6 & 1,1278 \\
\cline { 2 - 6 } & 80 & 20 & 16,4 & 27,3 & 1,1224 \\
\cline { 2 - 6 } & 70 & 30 & 10,2 & 25,2 & 1,1116 \\
\cline { 2 - 6 } & 60 & 40 & 7,5 & 25,1 & 1,1115 \\
\hline \multirow{4}{*}{50} & 90 & 10 & 15,1 & 29,3 & 1,1218 \\
\cline { 2 - 6 } & 80 & 20 & 10,3 & 24,6 & 1,1097 \\
\cline { 2 - 6 } & 70 & 30 & 7,1 & 20,5 & 1,0920 \\
\cline { 2 - 6 } & 60 & 40 & 4,3 & 17,8 & 1,0812 \\
\hline
\end{tabular}

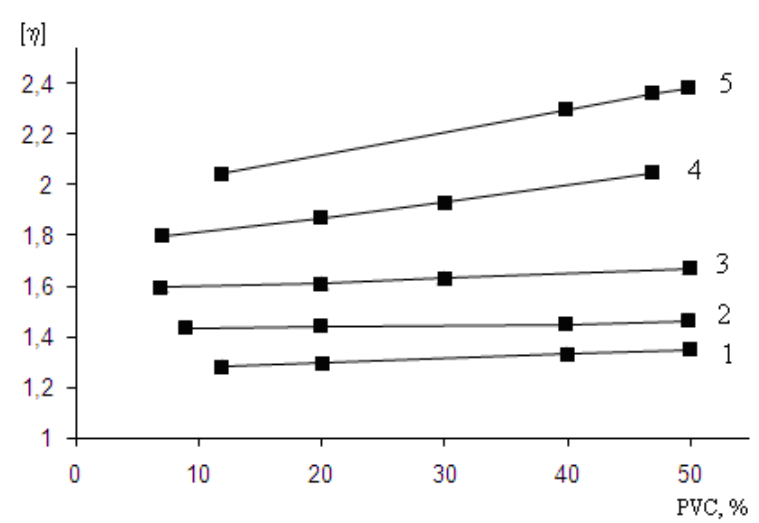

Figure 4. The characteristic viscosity $(\eta)$ of solutions of irradiated copolymers BNR-PVC (in acetone), obtained by irradiation doses (kGy): $1-10,2-20,3-30,4-40,5-50$

In present work BNR cross-linked by using doses showed in figure 4.

The cross-linked polymer SKN-40 after irradiation 50kGy destructed in polymer chain despites of presence double bonds in molecule. The increase of the characteristic viscosity of cross linked copolymers solutions (figure 4) with increasing radiation dose at which they were exposed, suggests the prevalence of cross-linking process in the copolymer chains.

\section{Conclusions}

1. In consequence of the thermodynamic research of solubility of the irradiated cross-linked copolymer of butadiene-nitrile rubber with PVC was founded that the scientific criterion of dissolvent power of the solvent is a changing of the solvent isobaric-isothermal potential in the polymer-solvent system, taking into consideration the dissolution process, i.e. enthalpy and entropy changes.

2. In the dissolution of the polymer a defining role plays energy effect and the small difference in the changes of thermodynamic functions. For the copolymer compared to the original polymer, as a result of radiation-chemical reaction indicates the absence of abrupt changes in solubility.

3. Using rheological studies for the study of molecular structural changes occur in the irradiated copolymer (BNR + PVC), gives an idea about character of change of solubility of the copolymers in acetone. Increasing of the absorbed dose due to a growth in the macromolecule chain mesh will lead to cross-linking and reduced solubility.

\section{REFERENCES}

[1] Kuzminskiy A.S., Fedoseva T.S., Makhlis F.A., Radiacionnaya khimiya polimerov. 1983. p.308

[2] Mamedov S.M., Yadreev F.I., Rivin E.M. Butadiennitrilniye kauchuki I rezini na ikh osnove. B.: 1991 Elm. p.308

[3] Bukhteew A.E., Chalykh A.E. IUPAC Macro 2008, Warsaw, Poland, 9-14 july 2008, vo 2, p.526.

[4] S.M.Mamedov, A.A. Garibov. Strucrural analysis of Advanced Materials. ICAAM 2009, Tarbes, France, September 7-10, 2009

[5] T.M. Ermolinskaya, L.A.Fenko, A.V.Bildukevich. Zh. Visokomol. Soed. 2009, vo. 50, no. 10, p.1802

[6] S.M.Mamedov, A.A.Garibov, G. Z. Velibekova. Khimiya visokikh energiy, vo. 44, No. 4 (2010), 268-271

[7] A.E.Chalikh, A.A. Borisevich, T.F. Petrova, Khimiya I khimicheskaya technologiya. 2010 vo. 58 , is. 10 , p.55

[8] Mamedov S.M. Chemical problems. 2006. №4 p.648

[9] Mamedov S.M. The fouth eurasian konference on nuclear science and its application. Baku, 2006. p.165

[10] Mamedov S.M. Kauchuk i rezina. 2009, №3 p.5

[11] Mamedov S.M., Qaribov A.A. Khimiya i khimicheskaya tekhnologiya. 2009.vo. 52, is. 12. p.93

[12] Mamedov S.M., Evstigneeva R.P., Saricheva I.K. Khimiya visokikh energiy. vo 25, no №5, 1991. p.438

[13] Mamedov S.M. Visokomolek. soed. 1991vo. 23.is.3. p.216

[14] Vaysverg A.Fizicheskiye metodi organicheskoy khimiyi. t.1. Izd. in. lit. M., 1987. p.108

[15] Kuznecov E.V., Divgun S.M., Budarina L.A. Praktikum po khimii i fiziki polimerov. M: Khimiya. 1987. p.380 